\title{
Redesign of a Service-learning Social Entrepreneurship Program for High School Students Part I: Design Research
}

\author{
Victor Udoewa \\ Deputy Director \\ $18 \mathrm{~F}$ Learn \\ Washington, DC 20006 \\ victor.udoewa@gsa.gov
}

\begin{abstract}
Started as a program in 2003 and then incorporated as a nonprofit in 2008, each year, LearnServe has taken students of diverse backgrounds from the Washington, DC area to experience a summer of international service-learning and social entrepreneurship. However, the students who travel abroad are not always prepared to go or able to successfully complete the post-trip activities. With experiences of extreme homesickness and severe culture shock, a lack of true social empowerment projects during the trip, and a lack of engagement in social entrepreneurship after the trip, the program directors realized there was a need to improve the LearnServe curriculum. The aim was to create an improved educational experience that prepares students to travel, engages them during the trip, and creates sharing and entrepreneurial opportunities afterwards. This paper presents the design research and prototyping work completed to redesign this service-learning program so that it meets its goals for success, more effectively preparing students to have a successful service-learning trip abroad and engaging social entrepreneurship work upon return.
\end{abstract}

Index Terms - high school, service-learning, Human-centered Design, social entrepreneurship

\section{INTRODUCTION}

In 2003, DC high school teacher Hugh Riddleberger received financial support from the Case Foundation and Share Our Strength, to take 14 students and 11 teachers from 6 different DC schools on a two-week, summer, service-learning trip to Ethiopia. ${ }^{1,2}$ The program became part of the Center for International Education at the Washington International School (WIS). Over the first three years, the program grew, adding trips to China, Zambia, and Paraguay. ${ }^{3,4}$

In the fall of 2006, the Center added a year-long after-school fellowship program in which 20 high school students learned social entrepreneurship skills and pitched venture ideas for funding in the spring. Then in 2008, the center left WIS and became an independent nonprofit called LearnServe. Since that time, Jamaica was added as a summer service-learning destination, replacing China and Ethiopia which are no longer destinations. The fellowship program also doubled to include 40 fellows. ${ }^{4}$

In 2013 as part of the 10th anniversary of LearnServe, ICF International was hired to conduct an impact evaluation of LearnServe, producing a LearnServe evaluation report. ${ }^{5,6}$ Due to the ICF findings and recommendations for deepening impact, in 2014, LearnServe launched an Incubator program and a Seeding Social Innovation program. ${ }^{7,8}$ The incubator provides a 2nd, postfellowship year of training for the most promising social ventures of alumni fellows. The Seeding 
Social Innovation program trains teachers to teach social entrepreneurship and innovation to their students as a school course.

However, the ICF report did not just identify ways to strengthen the fellows program or to better integrate LearnServe work with schools. It also identified ways to improve the summer abroad program, the flagship and original program of LearnServe. ${ }^{6}$

1. Increase communication between LearnServe groups within the same year

2. Help students more with the ongoing implementation of their ventures [though mainly for fellows, the summer abroad participants also create projects or venture]

3. Require students to fundraise at least a portion of their trip expenses

4. Turn LearnServe into a workable curriculum

5. Eliminate barriers to participation for lower income students that have transportation issues

6. Create a more formalized curriculum for Abroad trip leaders

Recommendations 4 and 6 both directly relate to the curriculum whereas recommendations 1 , 2,3 , and 5 indirectly relate to the curriculum. The curriculum consisted of 4 pre-trip sessions, the trip, and 3 post-trip sessions (Table I). ${ }^{9}$

\section{TABLE I}

Original LearnServe Curriculum

\begin{tabular}{|l|l|}
\hline Session & Content \\
\hline $\begin{array}{l}\text { Session 1: March 15, 2015 } \\
\text { [with parents, students ,teachers] }\end{array}$ & $\begin{array}{l}\text { Kick-off: Introduction approaches to development (quote } \\
\text { activity), } \\
\text { Program overview } \\
\text { Leadership reflection } \\
\text { Overview logistics, incl. passports, forms } \\
\text { Fundraising workshop } \\
\text { Parents and students to meet trip leaders }\end{array}$ \\
\hline Session 2: April 19,2015 & [Notary Public on hand] \\
\hline Session 3: May 16,2015 & $\begin{array}{l}\text { Ropes course (team building) } \\
\text { Country knowledge } \\
\text { Introduction partner organizations } \\
\text { Activity planning for trip, including lesson planning } \\
\text { Fundraising check-in }\end{array}$ \\
\hline Session 4/5: June 13/14, 2015 & $\begin{array}{l}\text { Cross-cultural Understanding: OUDC workshop, Nacirema lesson } \\
\text { Social entrepreneurship in developing countries: Albina Ruiz } \\
\text { video and role play; } \\
\text { Community based development - listen to people in country; }\end{array}$ \\
\hline
\end{tabular}




\begin{tabular}{|l|l|}
\hline & $\begin{array}{l}\text { Leadership reflection; } \\
\text { Last minute logistics }\end{array}$ \\
\hline Travel: June 23 - July 8, 2015 & $\begin{array}{l}\text { Volunteering } \\
\text { Peer-to-Peer exchange } \\
\text { Reflections } \\
\text { Leader for the Day } \\
\text { Blogging } \\
\text { Action Planning }\end{array}$ \\
\hline Session 6: August 29, 2015 & $\begin{array}{l}\text { Post-trip check-in (reflection: what changed for you because of } \\
\text { the trip?), Storytelling workshop, } \\
\text { Action planning }\end{array}$ \\
\hline Session 7: September 19,2015 & $\begin{array}{l}\text { Practice public presentation about action plan with external } \\
\text { reviewers }\end{array}$ \\
\hline Session 8: October 17, 2015 & Graduation \\
\hline
\end{tabular}

Used before, during, and after the summer abroad trip, the summer abroad curricular problems were numerous. Ultimately the pre-trip curriculum did not adequately prepare students for the trip as many experienced extreme culture shock and homesickness. Moreover, the trip curriculum did not always allow strong opportunities for learning social entrepreneurship. Most importantly, the post-trip curriculum did not engage many students and most did not complete the post-trip venture or social entrepreneurial activity. Unlike the YES International Summer Service program which started after LearnServe but has won national awards, the LearnServe curriculum was not designed by a learning designer or instructional designer. ${ }^{10}$

The author was hired to help redesign the curriculum so that the curriculum contributed to a successful LearnServe Abroad program for the vast majority of students. Though we had many questions to answer in redesigning the LearnServe Abroad curriculum, the main challenge was to answer our framing questions.

1. What are the various problems, issues, and difficulties students experience on the trip and throughout the LearnServe Abroad educational experience?

2. Why are students experiencing those problems and difficulties during the LearnServe Abroad educational experience?

3. What are the various skills and abilities students need to be able to do in order to complete a successful LearnServe Abroad educational experience?

In answering these questions, due to time and budget constraints, we follow the minimum viable research protocol of Erika Hall. ${ }^{11}$ 
International Journal for Service Learning in Engineering, Humanitarian Engineering and Social Entrepreneurship Vol. 13, No. 2, pp. 79-92, Fall 2018

ISSN 1555-9033

\section{Methodology}

The most important factor in determining which research methodology to use is the research question $^{12}$. Because our research question are open-ended, lack a specific hypothesis, and seek to uncover the mindsets, motivations, beliefs, hopes, fears, problems, and difficulties of students during the duration of the program, including pre-trip and post-trip education, a qualitative research methodology is best.

However, the answers to the questions will be used in an initial design. Since all three questions are used to redesign the LearnServe summer international service-learning program (LearnServe Abroad), we also need a design experiment or design-based research methodology. Design-based research (DBR) is characterized by pragmatism (solving current, real world problems), theory (producing learning theories based on research and testing of designs), iterations (using an iterative design process), integration (integrating multiple research methods), and contextualization (local design for local communities $)^{13-14}$.

Because DBR often is initiated by educational researchers as opposed to practitioners and may never be implemented in an actual learning environment, we employ a more narrow version of DBR called Design-based Implementation Research. Design-based Implementation Research (DBIR) has 4 guiding principles. These include jointly negotiated work (though this work was requested by LearnServe staff, it came about due to comments and complaints by students, teachers, and chaperones who noted a number of problems and a need for a new curriculum), iterative and collaborative design processes (our design team includes actual students who have participated in LearnServe Abroad trips), development of theories (theories guide and emerge from our design research and work), and design for viability (our goal is a sustainable curriculum that can grow and adapt with student needs $)^{15-21}$.

Design-based Research, in general, does not have to use a mixed methodology, though sometimes it does. In this case, we are combining DBIR with a qualitative methodology; therefore we chose the mixed methodology called Human-centered design (HCD, user-centered design, or design thinking) as our overarching framework because it combines a qualitative methodology with DBIR ${ }^{22-25}$. In education, HCD is often called student-centered design or learner-centered design (LCD). Human-centered design is only a methodology, not a solution. It can be used to design a building, a project, software, a process, a service, a product, an environment, a program, an organization, or even a curriculum. Human-centered design mixes skills from engineering design such as defining the problem, setting the constraints, and rapid prototyping with practices from the social sciences such as ethnographic studies, interviews, extracting insights from qualitative data, and empathic immersion ${ }^{26-29}$. In short, human-centered design keeps the design work centered on the users, the beneficiaries, or the community. In this work, HCD creates two pillars. First, instead of the traditional model where the designers go away, design a solution, and then bring it back to the community, in HCD, we practice participatory co-design where the community is involved in every stage of the design process ${ }^{30-32}$. Second, instead of the design team only including members from outside the community, we use a more narrow version of participatory co-design in which the design team also includes actual LearnServe Abroad students and alumni.

In this work, the design team includes 2 designers and 4 LearnServe Abroad students. Those students were involved in every stage of the work. 
Learner-centered design is normally broken into three stages, Discover, Design, and Deliver. The first stage (Discover) is a research stage where you listen and learn from the community for whom and with whom you are designing, developing empathy and connecting yourself to the needs and desires of that community. The second stage (Design) is a stage of data analysis and synthesis of the previous qualitative and quantitative work, followed by ideation, prototyping, feedback, refinement, and iteration. The final stage (Deliver) is the stage of pilot planning, developing a feedback loop, defining success, partnerships, and developing business models for financial viability and sustainability.

The remainder of the paper is broken into a few remaining main sections. First we provide a brief overview of the procedures and methods used in the first half of the LCD process (Discover and first half of the Design stage). Then we provide the results of the synthesis process: themes, insights, frameworks, and learning theories. Finally we provide the results of the remainder of the Design stage -- our working prototype of a new educational experience designed to reach success as defined by the program.

\section{Learning Theories}

In DBIR, learning theories both guide and emerge from the research and design. Such learning theories do not refer to overarching theories such as constructionism or experiential learning, but rather smaller learning theories dealing with the specific context of the educational intervention ${ }^{33}$. If we had an established learning hypothesis we wanted to test, a quantitative research methodology may have been more appropriate ${ }^{12}$. In this case, however, the initial thoughts of the design team were driven by two theories about the LearnServe program based on our experience and previous work designing the award-winning YES International Summer Service (YISS) Program ${ }^{10}$.

First, from an initial, cursory look at the overall curriculum structure (Table I), the learning team felt strongly that any educational program that prepares students for a multi-week or monthlong, international, service-learning trip, in a country with a different language or dialect, must meet much more than 4 or 5 times before the trip and will most likely need to meet throughout the year for sufficient preparation. The list of skills to learn and tasks to prepare is too long to be accomplished adequately in that time. Four or five sessions may not even be enough to develop strong intra-team dynamics for the country-student groups. There are multiple paid programs in which students pay money for a unique, cultural experience abroad without ever meeting the other students participating or only meeting them once. However, in those cases, the students are not trying to start or advance local social enterprises in the country abroad and in the US. On top of the languages skills, cross-cultural skills, teamwork, leadership, networking skills, influencing skills, and other social skills, students also need specific local development skills, entrepreneurial skills, participatory design skills, project-based skills, fundraising skills, coping skills, problemsolving skills, critical thinking skills, and more. These cannot be developed in 4 or 5 sessions unless the program is choosing students with all or most of those skills already. The YISS Program, in contrast, meets weekly throughout the entire year like a school club so that students are preparing in the autumn, winter, and spring for the summer trip.

Second, the learning team theorized that the curriculum needed to transition to experiential, problem-based learning (PBL). Problem-based learning is a type of inquiry-based model of learning in which learners work collaboratively to solve complex, real-world problems through 
which they not only acquire and develop knowledge but also skills and attitudes. It involves selfdirected, open-ended learning in which teachers serve in the role of facilitators ${ }^{39}$. Adhering to the best research in andragogy (adult learning theory), the design team wanted to ensure that the skills gained were situated in the contexts of the international service work the learners would be doing ${ }^{41-}$ ${ }^{42}$. Otherwise, a skill learned in one context may not necessarily transfer to a second context, and can actually be considered a different skill due to the different context, according to situated learning theory ${ }^{43,44}$. Our theory was that the learners in LearnServe Abroad must learn project skills in the context of community development and social entrepreneurship work that requires those skills, not by talking about it. Additionally, our theory was that a 4 or 5 knowledge-based sessions are not designed to produce skills. The curriculum needs skill-based educational experiences instead.

Third, the design team sensed that the education experience contained unnecessary lessons or components that did not contribute to a successful trip or entrepreneurial venture and should possibly be removed. To elaborate, an all-year, long-term educational experience (mentioned in the first theory), not only allows sufficient time for repeated application, mastery, and retention of the skills needed on the trip and after the trip in the US, but it also helps spread out the learning. Instead of concentrating abstract learning through most of 4 or 5 sessions and saving application on the trip when students find out they are not able to apply it, the design team hypothesized that learning would be improved if application was spread out through the educational experience prior to travel. In that type of design, the design team hypothesized that learning would be maximized if the learners learned only what they needed when they needed it. This type of just-in-time learning allows the service-learning and PBL educational challenges to dictate what learners needed to learn, in context and in the moment ${ }^{45-46}$. Just-in-time learning would increase retention of the skills rather than overloading students with too much knowledge and no application time prior to going abroad. Moreover, the design team hypothesized that the educational curriculum lacked a backward design process in which the assessment and final project (in this case, the trip activities and post-trip projects) are designed first and then the education is designed to exactly align and map to the assessments, preparing students specifically and only to be able to pass or master the assessment or final project ${ }^{47-49}$. The design team hypothesized that the curriculum needed a backward design process to improve learning.

\section{Procedures and Methods}

The team convened to first define the design challenge, constraints and preferences. In defining the design challenge the design team worked with the LearnServe COO because the design challenge needed to incorporate a definition of success. Without a definition of success, the design team could not uncover an answer to research question 3: What are the various skills and abilities students need to be able to do in order to complete a successful LearnServe Abroad educational experience? Built into the design challenge below is an implicit definition of what success is, enough to guide the design team to uncover the appropriate skills needed.

How can we create engaging, student-centered, educational experiences that build teamwork skills, prepare students for the LearnServe Abroad program, and empower them to take positive, sustainable, social action to solve problems inspired by their experience abroad? 


\title{
- Constraints
}

\author{
$\circ$ Engaging \\ ○ Builds teamwork skills
}

\section{- Preferences}

\section{- Incorporates culture of host country}

The constraints, built into the design challenge, are characteristics of the solution that are required for it to work. The preferences are desired characteristics of the solution without which, the solution still works.

The team, then, conducted a knowledge inventory, a method that elicits what team members know (known knowns) about learner needs, what technology can help, what solutions have been tried in other areas, and early hypotheses that various team members hold about what will solve the problem. The method also elicits what team members still need to learn (known unknowns) about what learners do, think, and feel; how learners value different offerings; what future learner needs may be; and the various challenges to the implementation of any ideas or solutions. The resulting information is taken to highlight strengths, weaknesses, and tensions among the group in order to direct our research towards our weaknesses, tensions, and what we still need to learn.

\section{- Strongest team knowledge}

○ What people (or students) need

\section{- Weakest team knowledge}

- What do students do, think, or feel

- How do students value the curriculum

\section{- Tensions that emerged}

- How to deliver education

- Use of phone during the trips

- Amount of preparational education needed

- Amount of academic preparation vs experiential learning

$\circ$ Which technology is inclusive

To address the weaknesses in knowledge of the design team, the team decided that the research should focus on potential and past student travelers as well as teacher chaperones to provide another perspective. To address the various tensions, the design team would design the interview guide to focus on the themes from the list of tensions as well as seek a well-rounded perspective of interviews from trip leaders, teacher chaperones, parents, administrative helpers, as well as students.

Using this information, the team set a goal to interview multiple trip leaders, teachers, students, parents, and school staff for all three current country destinations - Jamaica, Paraguay, and Zambia. However, recruiting was controlled by LearnServe. Unfortunately, LearnServe only gave contact information for a small group. If the goal is to interview multiple people in each of the 4 or 5 categories for each trip, the minimum goal was 24 to 30 interviews. According to best recruiting methods, that means we want to make sure to attempt to recruit at least 50-60 people because some 
people will not be interested, have time, be reachable, etc. ${ }^{50-51}$ However, we were only given contact information for 15 , so we expected to only interview about 8 (Table II).

TABLE II

ReCRUITMENT

\begin{tabular}{|c|c|c|c|}
\hline Country & Profile & $\begin{array}{l}\text { Number of contacts } \\
\text { received }\end{array}$ & $\begin{array}{c}\text { Number Responded and } \\
\text { Interviewed }\end{array}$ \\
\hline \multirow[t]{4}{*}{ Jamaica } & Trip leader & 2 & 2 \\
\hline & Teacher chaperones & 0 & 0 \\
\hline & Students & 0 & 0 \\
\hline & Parents & 1 & 1 \\
\hline \multirow[t]{4}{*}{ Zambia } & Trip leader & 2 & 0 \\
\hline & Teacher chaperones & 2 & 2 \\
\hline & Students & 4 & 2 \\
\hline & Parents & 1 & 0 \\
\hline \multirow[t]{4}{*}{ Paraguay } & Trip leader & 1 & 0 \\
\hline & Teacher chaperones & 0 & 0 \\
\hline & Students & 1 & 1 \\
\hline & Parents & 0 & 0 \\
\hline $\begin{array}{l}\text { Multiple } \\
\text { countries }\end{array}$ & School staff & 1 & 1 \\
\hline \multicolumn{3}{|c|}{ Total Interviewed } & 9 \\
\hline
\end{tabular}

The author served as logistician while the entire team helped to recruit people from the contacts given by LearnServe. We conducted 7 individual interviews and 1 group interview. This includes 1 school staff member, 3 students from Zambia and Paraguay trips, 2 Jamaica trip leaders, 2 
Zambia trip teacher chaperones, and 1 parent of a Jamaica trip student (Table II). All the following research methods were chosen and later employed.

- Individual interview - an interview with only one interviewed person

- Group interview - an interview in which questions are posted to a group and group members take turn individually answering

- Expert interview - an interview with someone who has a relevant expertise, in this case, education, service-learning programs, international development, community development, design, etc.

- Analogous inspiration - observation of a different context (of a mentoring program or training program) in order gain insight about designing something similar in your own context

- Community-driven discovery - co-participatory research in which the people for whom you are designing are also members of your design and research teams

- Background secondary research - researching similar programs and reading through the current curriculum to map all the competencies it covers including its modes of delivery

The team also incorporated several interviewing techniques including flash cards, guided tours, resource flows, etc..$^{23-24}$

Next, for the interviews, we chose a semi-structured interview approach, developed an interview guide, and then prepared and practiced interviewing other design research teammates. The preparation included training for bias awareness (discussing our previous experiences and backgrounds and how they affect our views), bias journaling (journaling about all the biases we bring to this work related to our experiences and thoughts about LearnServe, service learning, international development, etc.), observing versus interpreting (differentiating between objective observation [what we see] versus subjective documentation [what we infer or the effect of the lens through which we see]), and other interview techniques. These trainings were done in order to lessen the influence of our bias, biased interpretations, and preconceived notions of what we thought people needed or wanted. We wanted to let the qualitative data speak on its own.

We then conducted our interviews and background research throughout the Washington, DC area. After this step, we paused to reconsider the challenge. Often after conducting initial discovery research, we find that the the challenge is not actually a problem among those observed and interviewed. Or we may find the problem is too broad or too narrow. However, in this case, all team members agreed: our qualitative research confirmed the design challenge, so it was not changed.

In the next section, we conduct synthesis, code the stories and qualitatively analyze data to extract insights and find themes. Through further analysis we unearth frameworks as learning theories and program hypotheses emerge which guide is in prototyping.

\section{SyNTHESIS}

\section{Themes and Insights}

Key insights grouped by themes are seen in Table III. First, the research team deconstructed all qualitative data into single-idea, individual quotes, facts, and observations. Next, the research team grouped similar facts, quotes, or observations together to highlight patterns (right column of Table 
III) across interviews. Then the research team connected various quotes, facts, and observations to infer or extract hidden insights (right column of Table III) not directly captured in a quote, fact, or observation. The research team then grouped all insights, patterns, facts, quotes, and observations into broad categories or themes. We regrouped and regrouped the themes until we felt the final themes were on the same high level, spoke about similar things, and captured the emerging patterns in the data. All themes emerged in $100 \%$ of all interviews. The final high-level themes are in the left column of Table III. Because insights do not capture all of the data (facts, quotes, observations), it is important to highlight crucial points or patterns throughout the data. Also due to the large number of insights, we want to summarize the important points in each theme that shape the future redesign of the LearnServe Abroad curriculum.

TABLE III

Insights And Patterns Grouped by Themes

\begin{tabular}{|c|c|}
\hline Themes & Insights and Patterns \\
\hline $\begin{array}{l}\text { Attendance, } \\
\text { Behavior, \& } \\
\text { Rules }\end{array}$ & $\begin{array}{l}\text { 1. Students from low income families or those who receive financial aid seem } \\
\text { to have behavioral issues that prevent them from receiving the most from } \\
\text { the trip experience. } \\
\text { 2. Meeting location, accessibility, and consistency can be difficult and a } \\
\text { deterrent for student participants. } \\
\text { 3. Attendance strongly affects learning and trip experience. }\end{array}$ \\
\hline $\begin{array}{l}\text { Personal } \\
\text { Development }\end{array}$ & $\begin{array}{l}\text { 1. Students who have not traveled before struggle more than others with } \\
\text { adjusting to differences in the foreign country, but have more } \\
\text { transformative experiences. } \\
\text { 2. Massive growth occurs during the trip. } \\
\text { 3. When properly executed, the program has a multitude of growth } \\
\text { opportunities. }\end{array}$ \\
\hline $\begin{array}{l}\text { Background, } \\
\text { Promotion, and } \\
\text { Selection }\end{array}$ & $\begin{array}{l}\text { 1. There are multiple selection processes, both internal to the school and } \\
\text { external across the city. } \\
\text { 2. The selection process also affects the educational experience of } \\
\text { participants. } \\
\text { 3. Multiple learning problems arise from the selection process, the trip } \\
\text { creation process, logistics, etc. } \\
\text { 4. Students and trip leaders apply for a multitude of reasons not necessarily } \\
\text { aligned with LearnServe objectives. }\end{array}$ \\
\hline $\begin{array}{l}\text { Entrepreneurship } \\
\text { \& Sustainability }\end{array}$ & $\begin{array}{l}\text { 1. Social entrepreneurship education is not strong and usually lacking, } \\
\text { especially in the area of sustainability. } \\
\text { 2. The social divisions in Washington, DC are a barrier to continuing } \\
\text { relationships among participants. } \\
\text { 3. Overseas activities sometimes lack sustainability or purpose. }\end{array}$ \\
\hline $\begin{array}{l}\text { Motivation \& } \\
\text { Commitment }\end{array}$ & $\begin{array}{l}\text { 1. There are participants who do not care about the trip. } \\
\text { 2. LearnServe trip leaders with full scholarship show full commitment, } \\
\text { whereas receiving full funding, as a student, lowered commitment. } \\
\text { 3. Fundraising creates sense of ownership and commitment. }\end{array}$ \\
\hline
\end{tabular}




\begin{tabular}{|c|c|}
\hline & $\begin{array}{l}\text { 4. Students, chaperones, and leaders felt disengaged from in-country } \\
\text { activities for which they did not see meaningful or sustainable ends. }\end{array}$ \\
\hline Trip Activities & $\begin{array}{l}\text { 1. Educational preparation, trip activities, service work, and LearnServe goals } \\
\text { not aligned or coordinated. } \\
\text { 2. There is a lack of focus in trip activities. }\end{array}$ \\
\hline Logistics & $\begin{array}{l}\text { 1. There is no consistent LearnServe Abroad experience across country trips, } \\
\text { years, or student types. } \\
\text { 2. The LearnServe staff is viewed favorably for delivery of sessions. } \\
\text { 3. Communication problems with parents negatively affect the image of } \\
\text { LearnServe. } \\
\text { 4. There is a conflict between the "no electronics" rule, a lack of connectivity } \\
\text { on trips, and the required blogging during the trip. }\end{array}$ \\
\hline Fundraising & Students do not have sufficient time or guidance to reach fundraising goals. \\
\hline $\begin{array}{l}\text { Knowledge \& } \\
\text { Cultural Context }\end{array}$ & $\begin{array}{l}\text { Students and trip leaders experience a lack of sufficient cultural, historical, } \\
\text { geographical, and linguistic understanding. }\end{array}$ \\
\hline $\begin{array}{l}\text { Energy \& Group } \\
\text { Dynamics }\end{array}$ & $\begin{array}{l}\text { 1. Cross-cultural communication is a needed skill both abroad during the trip } \\
\text { as well as within student trip groups with students from various parts of } \\
\text { DC. } \\
\text { 2. Pre-trip education does not fully unite the group, but the bonding process } \\
\text { continues on the trip. } \\
\text { 3. Students lack the ability to maintain high energy for less glamorous } \\
\text { activities during the trips. } \\
\text { 4. Camping was a negative experience for some kids on the trip. }\end{array}$ \\
\hline Curriculum & $\begin{array}{l}\text { 1. The curriculum is not cumulative and not mastery-based. } \\
\text { 2. The curriculum does not properly assess or prepare skills needed for the } \\
\text { trips. } \\
\text { 3. The curriculum design, alone, cannot address all problems. } \\
\text { 4. There is not enough pre-trip preparation time for all the skills and } \\
\text { knowledge needed. } \\
\text { 5. Students, teachers and chaperones acknowledge that key soft skills and } \\
\text { maturation seem to positively benefit and prepare students before the trip. } \\
\text { 6. The LearnServe Fellowship program does a better job creating educational } \\
\text { experiences to learn same skills. } \\
\text { 7. At the beginning of the curriculum, the ropes course is fun, and it begins to } \\
\text { teach team building; but the value is debatable in light of poor team } \\
\text { dynamics on some trips. } \\
\text { 8. Students do not all learn intangible and soft skills through the program. }\end{array}$ \\
\hline
\end{tabular}




\begin{tabular}{|l|l|}
\hline Skills & $\begin{array}{l}\text { 1. Top skills needed are communication, adaptability, and (if doing actual } \\
\text { service work) understanding needs (empathy). }\end{array}$ \\
& $\begin{array}{l}\text { 2. Secondary skills needed are ethics/respect, open-mindedness, creativity, } \\
\text { perseverance, and teamwork. } \\
\text { Important gaps in pre-trip education exist including coping training. }\end{array}$ \\
\hline $\begin{array}{l}\text { Post-trip Projects } \\
\text { \& Presentations }\end{array}$ & Student projects lack feasibility or sustainability. \\
\hline
\end{tabular}

- Skills - The design team conducted an inventory of the activities done on the overseas service-learning trips as well as the skills required to satisfactorily and successfully complete those activities. The top skills needed for the trip are communication skills (including cross-cultural communication skills), adaptability, and empathy. These skills were extracted from $100 \%$ of interviews and trip summaries. Secondary skills needed include ethics, respect, open-mindedness, creativity, perseverance, and teamwork. Each of these skills were extracted from the activities mentioned in at least $50 \%$ or more of the interviews. The most impacting skills gap causing trip failure for students, according to the design challenge, was a lack of coping skills which falls under adaptability. There are reports of students retreating inward due to the experience, refusing to each much, or needing to call home every day, for example. The skills analysis leads to the next question. How well does the curriculum help students master these skills?

- Curriculum - Based on the skills analysis, the design team analyzed the curriculum both directly and indirectly through student-reported impact and experience during interviews. First, the curriculum is not mastery-based, nor cumulative. ${ }^{52-55}$ In other words, it does not wait for mastery of one learning objective before moving on to other learning objectives, and the curriculum does not build and integrate previous learning objectives for improved practice, application, and retention. Second, the curriculum was not designed with any assessment to measure student progress or achievement of any learning objectives. So there is no way to know if the students are learning what is needed for a successful trip. Third, related to this, the curriculum fails to properly prepare students in a number of ways. Students do not learn any of the soft or intangible skills needed for the program like communication, perseverance, creativity, etc. There is one curricular session focused on team work - a ropes course - that students enjoyed. However, according to research, student satisfaction has a little or no correlation with student learning, and the value of this ropes course session is debatable given poor team dynamics on the service trips. ${ }^{56-59}$ The most important finding is that the LearnServe Abroad program does not include sufficient time to learn, practice, and master the needed skills in preparation for travel and service. In fact, according to interviews, the LearnServe Fellows program, which works like an afterschool program, does a better job of preparing students for the same skills by having many more sessions throughout the entire year.

- Effects of Curriculum on Learning - Due to poor or suboptimal curricular design, multiple learning problems and skill gaps emerge.

- Fundraising - Because the curriculum does not use sufficient time for students to learn, practice, and master various skills, different skills suffer. There is an entire 
session donated to fundraising (Table I), and still students do not have sufficient time or guidance to reach fundraising goals.

- Knowledge and Cultural Context - Multiple students, trip leaders, chaperones, and parents commented that the participants simply did not know enough or much about the country they visited. Beyond just a lack of geographic, historical, and broadly cultural knowledge, the biggest impact was a lack of linguistic skills. It completely affects the ability of students to communicate outside of English-speaking contacts, guides, and tour providers and limits the work, experience, and impact of the trip. This aligns with research that says language is the biggest part of a culture. ${ }^{60-62}$

- Energy and Group Dynamics - As stated earlier, the ropes courses in the curriculum has not been sufficient to ensure, or even increase the likelihood of strong team bonding by the start of the trip. Moreover, many of the socio-cultural divisions that exist between students from different socioeconomic neighborhoods and schools in Washington, DC, still exist and divide students during the trip. The design team extracted cross-cultural communication as one of the three primary learning needs, not just because it impacts the interactions between students and people they meet abroad, but because it is hugely important between different student cultures within the same trip group. Because LearnServe pulls students from different schools and neighborhoods across DC, this is an additional hurdle to overcome. It does not necessarily mean that students are sent home early due to failure to work together (though it has happened at least once), but it does mean that the work is less impactful due to a lack of bonding between groups. This is also observed in the lack of continued relations and interactions of students from different neighborhoods after the trip. It has happened in a few cases, but overwhelmingly post-trip relationships end. Lastly, the curriculum does not prepare students for the nonglamorous work during the trips so that students are uncommitted to the work or completely shocked by it. One example is camping in which students unused to the experience felt culture shock during camping, wanted to go home, cried, ate very little, or took no baths due to the condition of the bathrooms, if any.

- Post-trip Projects and Presentations - The curriculum includes learning activities both before, during, and after the trip. After the trip, the LearnServe Abroad students, using their trip experience, are supposed to create social entrepreneurial initiatives and present on their achievement, success, effectiveness, or outcome. At least half of the students failed to do a project. Some students did not any attend any number of post-trip sessions including all of them. The vast majority of students who attempted projects brainstormed projects that were either infeasible or unsustainable. The infeasible projects had little implementation, as a result. The unsustainable projects quickly ended after the program since there was no way to sustain them. These projects are a key purpose of the entire LearnServe program and demonstrate a failure of the program and curriculum.

- Effects of Program Design on Learning - Often times, executives of organizations relegate curricular design to learning designers, not understanding or realizing that learning designers design programs, services, games, software, and much more. ${ }^{10}$ Anything that affects learning should have an instructional design perspective involved. Similarly here, 
the educational program design has large effects on learning even though LearnServe did not involve learning designers in the design of the program.

- Attendance, Behavior, and Rules - The program design brings students from different neighborhoods and schools on the same trip, as opposed to placing students from the same school on the same trip. LearnServe, however, does not rotate its meeting places throughout the city. Unfortunately, the meeting locations are biased towards higher socioeconomic neighborhoods that are accessible by subway. This means that access to the educational trip meetings was restrictive for students in African-American dominated, lower-income neighborhoods within the city, either due to money required for transport or length of travel. When LearnServe has tried to change locations, inconsistent meeting locations became a problem for students as well. Attendance is important because it strongly impacts learning and the overall trip experience. Additionally, interviewees noted that students receiving financial aid or from low-income communities tended to have more behavioral issues which prevented them from receiving the full benefits of the program.

- Background, Promotion, and Selection - The promotion and selection process greatly affects the educational experience, most notably because students less likely to be enriched by the program are sometimes selected over those more likely to be enriched. Although, LearnServe Abroad was intended for students without the financial means to go abroad, the organization cannot finance scholarships for all students. Therefore, it invites a mix of students, those who need financial help as well as those who can pay their way or whose school can pay their travel fees. This creates a mix of people who have never traveled abroad (or even out of state) with people who have traveled abroad and would have done so anyway without the program. Yet it is the ones who have not traveled before who have the potential for the most transformative experience. Related to this is the tension of misaligned goals of the LearnServe Abroad program and student participants. Some students sign up just to have a good time or to travel, not to serve, start a social enterprise initiative, or engage in social entrepreneurship. This misalignment manifests itself in missed sessions, lack of follow-through in post-trip projects, and even lack of enthusiasm for service or entrepreneurial work during the trip. Additionally, it is difficult to select the best participants for each trip when there are multiple selection processes. Each school has its own process to nominate students who then compete across the city for a position on a trip team. Though, on its own, that type of double selection does not necessarily create a problem, in the LearnServe selection process, it results in LearnServe only seeing a filtered set of students who are not always the most well suited students for the program at the school. The schools do not necessarily use the same criteria that LearnServe uses.

- Entrepreneurship \& Sustainability - Additionally, the social entrepreneurship and sustainability component of the program is not well designed. All interview participants reported participating in trips that included activities that had no purpose or reason or where unsustainable. Secondly, there was no sustainability education in the curriculum to prepare them for trip activities or for post-trip sustainability work. Finally, the vast majority of intra-Washington, cross-cultural 
relationships did not sustain after the program ended for participants. The vast majority of projects also did not sustain.

- Trip Activities - As stated earlier, the trip activities tend to be unsustainable or without purpose. The activities themselves do not align around a common entrepreneurial or development theme for each trip. Ultimately, there is a consistent lack of alignment between the LearnServe goals of social entrepreneurship and sustainability, educational preparation for the trip, trip activities, and service work. This makes it difficult for success to be achieved when each of those components fails to reinforce the goal.

- Motivation and Commitment - The aforementioned misalignment leads students and chaperones and leaders to feel disengaged from trip activities in which they saw no purpose or meaning. Additionally, the selection processes does select and send students abroad who actually do not care about the trip. Interestingly, fundraising created a greater sense of ownership among student participants, whereas receiving full funding lowered commitment for student participants. To contrast, trip leaders who received full funding show full commitment.

- Logistics - The aforementioned problems in program design can be summed in logistics. Ultimately, there is no consistent LearnServe Abroad experience across different years or country trips or even student types. This inconsistency is, in part, due to a lack of communication between trip leaders, country hosts, and pre-trip session facilitators, creating a lack of alignment between program goals, pre-trip educational goals, and trip goals and activities. Moreover, the communication problem extends to parents who had a negative view of the program due to not receiving enough information ahead of the trip. One example of misalignment and miscommunication is the programs "no electronics" rule which conflicts with program requirement that students blog during the trip which again conflicts with a lack of connectivity during the trip. Still, at least in terms of the delivery of the sessions (not content or outcomes), the LearnServe staff is viewed favorably by participants and leaders and chaperones.

- Personal Development - Though students who have not traveled before struggle more than others, they have the most transformative experiences beyond those who have traveled before or whose goals do not align with the program goals. In fact massive growth occurs during the trip. When executed properly, the LearnServe Abroad trips have multiple opportunities for growth for participants.

\section{Learning Theories}

None of the three learning theories were upended; instead, they were validated. First, the research found that 4 or 5 sessions was not enough to learn, practice, master, and retain the skills found to be necessary for a successful trip and post-trip, sustainable project in social entrepreneurship.

Second, based on research insights, the LearnServe Abroad curriculum needs to transfer to an experiential, problem-based, project-based, or exploratory learning paradigm. In other words, it needs to move to a skills-based curricular model. One goal of educational research is to uncover the knowledge and skills needed to accomplish a goal. When the design team applied research techniques to uncover the knowledge and skills needed for LearnServe Abroad, the team found 
that the overwhelming need for student participants are skills (which come with corresponding knowledge), rather than knowledge alone. In stark contrast, the LearnServe Abroad curriculum is dominantly knowledge-based. It is extremely difficult for participants to learn, master, and retain skills through a knowledge-based educational experience. ${ }^{63-64}$ The only two components of the LearnServe Abroad curriculum that arguably could be called skills-based are the ropes course to establish team building skills and the session on fundraising which does not reinforce fundraising skills but, rather, teaches knowledge about fundraising and helps them set up an account on an online fundraising platform. Educational research and practice show that skills and knowledge work together; however, the LearnServe Abroad curriculum is severely lacking skills-based educational experiences for the skills they must be able to use abroad during their trips and for their post-trip social entrepreneurial initiatives. ${ }^{65}$

Third, based on our analysis of the learning needs for a successful trip and post-trip social enterprise project, the LearnServe Abroad curriculum does contain superfluous information. Such knowledge is fine to include as long as it is not at the expense of skills-based learning needed for the trip and project. A good example is a lesson on the Sustainable Development Goals (SDGs) developed by the UN. ${ }^{66}$ It is possible to learn the needed skills and experience a successful trip and create a sustainable social enterprise that outlasts student involvement in the program without knowing anything about the SDGs. With time constraints such as 4 or 5 meetings, it is important to focus the learning on the essential learning needs for the trip and social enterprise initiative.

\section{Frameworks}

Frameworks are visual representations of a system of relationships. Theses visualizations of systems help designers understand what to consider when designing and what parts of a system might fail if not addressed. In this work, we create three frameworks during the synthesis process - journey maps, personas, and a relational map.

\section{Student Journey through the Program}

In conducting research on the LearnServe program, the research team discovered that, because there was no requirement to attend all 4 or 5 pre-trip sessions or any of the 3 post-trip sessions, students have radically different paths and experiences through the program based on attendance (Figure I). Instead of visualizing all pathways through the program, the research team chose to 
International Journal for Service Learning in Engineering,

Humanitarian Engineering and Social Entrepreneurship

Vol. 13, No. 2, pp. 79-92, Fall 2018

ISSN 1555-9033

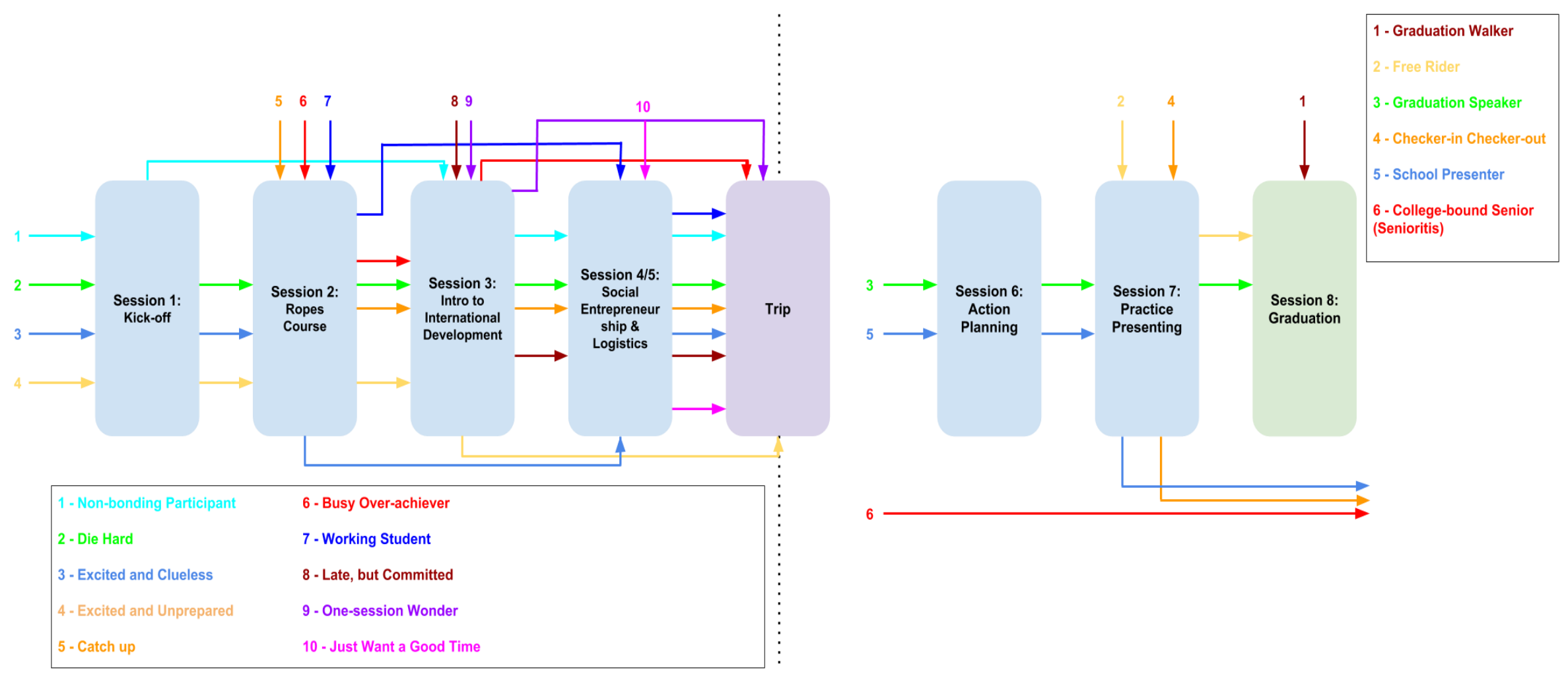

FIGURE I

STUDENT JouRnEYs 
diagram pre-trip experiences and post-trip experiences separately for simplification. Not all possible journeys were mapped as we based it on our research. It is possible those journeys existed and we did not speak with people who took that path. To illustrate, we do no include a journey were a student only attends the trip with no pre-trip sessions as this does not occur at all. We also do not include journeys that miss the trip since we are mapping student experiences that include the trip to understand how prepared those students are and how successful the trip and post-trip activities are. In summary, we do not map the following journeys.

1. Trip only with no preparatory sessions

2. Drop-out journeys that do not attend the trip

3. Session 1 and/or Session 2, followed by the trip (no Sessions 3-5)

4. Session 1 and Session 3, followed by the trip

5. Session 1 and Session 4/5, followed by the trip

It is also important to note that the research team did not separate sessions 4 and 5 because they occurred together, back to back with no break over two days. Among those the team interviewed, students either attended the blocked sessions or missed them.

Similarly, for the post-trip sessions, we do not include journeys of students who only attend session 6 and drop out, or students who attend session 6, skip session 7, and attend graduation. Again, it is possible these journeys occur, and further research will bear that out.

The journeys help visualize the widely different experience students have. Even if the curriculum does not fully prepare students, the journey map illuminates that many students do not even receive the full import of the curricular sessions. To explicate, many of the journeys, in Figure I, have been named to capture what was learned or missed. For instance, Path 1 is named the "Nonbonding Student" because this student missed the team bonding session. Path 8 is named "Late, but Committed" because this student missed the kick-off and team-bonding sessions but went to every session after that before attending the trip. Similarly in the post-trip sessions, Path 1 is named "Graduation Walker" because this student simply shows up for the graduation ceremony and nothing else. Path 3 is named "Graduation Speaker" because this student attends every post-trip session and completes a post-trip, sustainable project which is why she was chosen to speak at the graduation ceremony.

The second illumination we see from the journey maps is that the preparation for the trip and the post-trip, sustainable, social entrepreneurship project are unequal. There are more preparatory sessions for the trip which involves activities over two weeks, than for the sustainable, social enterprise project which theoretically last forever. Moreover, given that session 8 is graduation and session 7 is practicing presenting about your project, only session 6 is dedicated to help support the project. This is the opposite of what is expected as a sustainable, social entrepreneurship project needs even more preparation and ongoing support to ensure success which is what the LearnServe Fellowship program does but is not done in the LearnServe Abroad program. It is important to note that pre-trip sessions and trip activities could help support the future student initiatives; however, due to a lack of alignment, this is not usually the case. 


\section{Participant Personas}

The path names in the journey maps (Figure I) are a reminder of various, potential, design personas. A design persona is a fictional generalization of a group of users (or students) who share similar needs, behaviors, pain points, and motivations. Based on qualitative and quantitative research, they are a way to concisely communicate synthesized research, develop empathy for the users, make design decisions, focus design work, and even test effectiveness. Though a controversial topic in the academic realm of design research, the design team, in this work, wanted to use personas to help guide future designs of the curriculum.

Six design personas are listed below - 2 teachers and 4 students (Table IV). Since only one non-teacher chaperone and only one parent were interviewed, personas were not created for them since there was no one to generalize with one data point. For brevity, persona pictures and narratives are not included.

\section{TABLE IV}

Personas

\begin{tabular}{|l|l|l|}
\hline Persona & \multicolumn{1}{|c|}{ Category } & \multicolumn{1}{|c|}{ Description } \\
\hline \multirow{5}{*}{ Matt } & Background & $\begin{array}{l}16 \text { years old; from Bethesda, MD; went to Whitman High } \\
\text { School (public); traveled 3 times (Europe, Hawaii, mission trip } \\
\text { to Oregon) }\end{array}$ \\
\cline { 2 - 3 } & Socio-economic level & Upper-middle class \\
\cline { 2 - 3 } & Education & 10 th grader \\
\cline { 2 - 4 } & Overall Attitude & Bored, nervous, excited about traveling somewhere exotic \\
\cline { 2 - 4 } & Key Needs & $\begin{array}{l}\text { Community service requirements, resume padding, international } \\
\text { experience }\end{array}$ \\
\cline { 2 - 4 } & Motivation & $\begin{array}{l}\text { New experiences, improving profile to obtain acceptance to a } \\
\text { good university }\end{array}$ \\
\cline { 2 - 4 } & Goals & 80 community service hours \\
\cline { 2 - 4 } & Challenges & $\begin{array}{l}\text { Communicating with kids from a different background, not } \\
\text { having wi-fi }\end{array}$ \\
\cline { 2 - 4 } & Tools and Skills & Writes well (AP English), accustomed to going abroad \\
\hline \multirow{2}{*}{ Russell } & Background & 24 years-old; teaches at Bullis in Silver Spring, MD \\
\cline { 2 - 4 } & Socio-economic level & Middle class \\
\hline
\end{tabular}


International Journal for Service Learning in Engineering,

Humanitarian Engineering and Social Entrepreneurship

Vol. 13, No. 2, pp. 79-92, Fall 2018

ISSN 1555-9033

\begin{tabular}{|c|c|c|}
\hline & Education & Masters in Education \\
\hline & Overall Attitude & Excited \\
\hline & Key Needs & $\begin{array}{l}\text { Good classroom management, scheduling, understanding the } \\
\text { trip }\end{array}$ \\
\hline & Motivation & $\begin{array}{l}\text { Cheap or free international trip, family member he wants to } \\
\text { visit, learning outside the traditional classroom, continuing } \\
\text { education }\end{array}$ \\
\hline & Goals & Fulfill motivations \\
\hline & Challenges & $\begin{array}{l}\text { Working all the time, adjusting to culture shock, dealing with } \\
\text { insubordinate students }\end{array}$ \\
\hline & Tools and Skills & Experienced teacher/leader, classroom management \\
\hline Shaniqua & Background & 18 years-old, student at Ballou \\
\hline & Socio-economic level & Lower-middle class \\
\hline & Education & 11th grader \\
\hline & Overall Attitude & Bored, unmotivated, not interested in learning, "sightseeing" \\
\hline & Key Needs & Fundraising enough money \\
\hline & Motivation & Still looking for what motivates her in life \\
\hline & Goals & Complete community service hours, go to college \\
\hline & Challenges & $\begin{array}{l}\text { Attitude, lack of adaptability, lack of interest, lack of some } \\
\text { literacy skills }\end{array}$ \\
\hline & Tools and Skills & "Street smarts" \\
\hline Makoyla & Background & $\begin{array}{l}17 \text { years-old, from Northeast DC, Went to EL Haynes Charter } \\
\text { School, }\end{array}$ \\
\hline & Socio-economic level & Lower-middle class \\
\hline & Education & 11th grader \\
\hline
\end{tabular}


International Journal for Service Learning in Engineering,

Humanitarian Engineering and Social Entrepreneurship

Vol. 13, No. 2, pp. 79-92, Fall 2018

ISSN 1555-9033

\begin{tabular}{|c|c|c|}
\hline & Overall Attitude & Intimidated, excited \\
\hline & Key Needs & Build resume, college preparation \\
\hline & Motivation & International experience \\
\hline & Goals & Gain admission into college \\
\hline & Challenges & $\begin{array}{l}\text { Foreign language, culture shock with other DC students and } \\
\text { international partners }\end{array}$ \\
\hline & Tools and Skills & $\begin{array}{l}\text { Good communication, open-mindedness, energy, interest, and } \\
\text { excitement }\end{array}$ \\
\hline Ashley & Background & $\begin{array}{l}34 \text { years-old teacher at Cesar Chavez Charter School from } \\
\text { Laurel, MD }\end{array}$ \\
\hline & Socio-economic level & Middle class \\
\hline & Education & Bachelors in Education \\
\hline & Overall Attitude & Excited, fearful \\
\hline & Key Needs & $\begin{array}{l}\text { Execute and communicate trip logistics, build teamwork, and } \\
\text { fundraise sufficient money }\end{array}$ \\
\hline & Motivation & Compensation, build new skills, international experience \\
\hline & Goals & $\begin{array}{l}\text { Successful trip, avoid logistical and health problems, teach } \\
\text { curriculum, maintain positive attitude, earn respect of team }\end{array}$ \\
\hline & Challenges & $\begin{array}{l}\text { Lack of unity in group of students, lack of student knowledge } \\
\text { about country }\end{array}$ \\
\hline & Tools and Skills & Previous leadership and international experience \\
\hline John & Background & $\begin{array}{l}\text { 17-year-old student at Burke from Woodley Park, DC, who has } \\
\text { traveled to Europe }\end{array}$ \\
\hline & Socio-economic level & Upper-middle class \\
\hline & Education & 12th grader \\
\hline & Overall Attitude & $\begin{array}{l}\text { Does not care, parents said he must go, "Been there" attitude, } \\
\text { glued to phone }\end{array}$ \\
\hline
\end{tabular}




\begin{tabular}{|l|l|l|}
\hline Key Needs & Service hours \\
\cline { 2 - 3 } & Motivation & Fun \\
\cline { 2 - 3 } & Goals & Complete service hours, sightseeing \\
\cline { 2 - 3 } & Challenges & $\begin{array}{l}\text { Communicating with kids from other backgrounds, following } \\
\text { directions, respecting others }\end{array}$ \\
\cline { 2 - 3 } & Tools and Skills & Some international experience \\
\hline
\end{tabular}

\section{Relational Map}

The final framework the research team created was a relational map visualizing how the different parts of the program design affect the student experience (Figure II). The purpose was to clearly illustrate what parts of a successful student experience are affected by the curriculum and what parts are not. That information, in turn, can be used to make recommendations about the program design, even though the organization requested only curricular design. However, both program design and curricular design are part of learning design and affect learning outcomes.

Starting in the bottom left region of Figure II, we see that the program design affects logistics and planning (e.g. country choice, trip duration), the promotion and selection process used to choose participants, and the curriculum (e.g. session duration, frequency, and number). One can understand the importance of program design when viewing that the logistics and planning affect trip activities and attendance at the educational sessions. First, trip activities that do not align with educational sessions, post-trip projects, or any theme is a source of frustration affecting student energy, dynamics, and learning on the trip. Second, the location choice and consistency affects who has transportation access to pre-trip, education sessions, usually to the disadvantage of lowerincome students.

Similar the promotion process can select students who have difficulty attending sessions in other parts of the city, students whose motivation does not align with the purpose of LearnServe, or even students with poor behavior in general. From day 1, even with an excellent curriculum, significant behavioral, financial, attendance, motivational problems can manifest. Definitely, a good curriculum can improve motivation, commitment, and behavior but non-curricular design effects can work against this. 


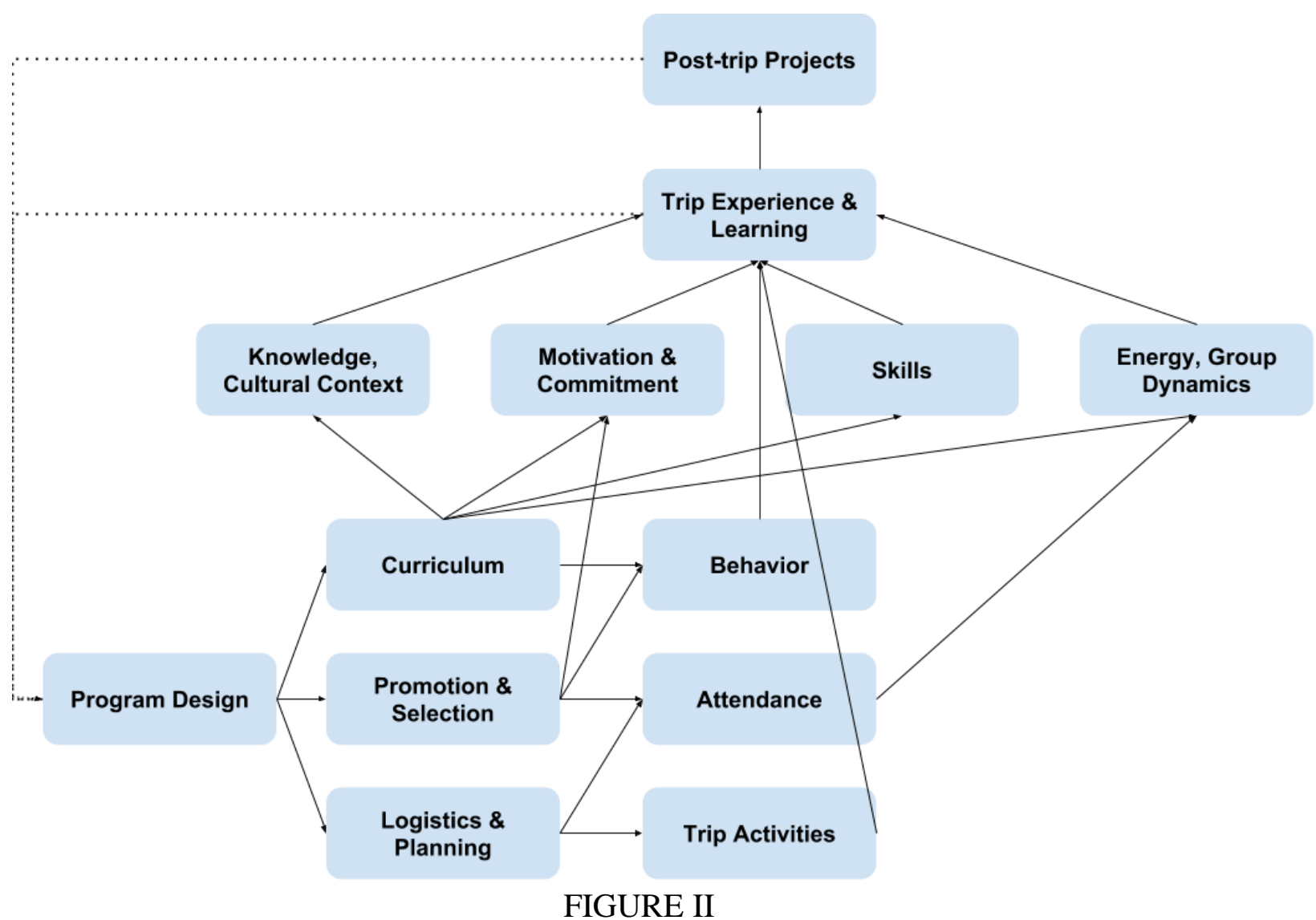

Relational Map of Program Components

The curriculum, then, affects the behavior and motivation as well as knowledge, skills, energy, and group dynamics. Each of those, in turn, affects the trip experience. But the trip experience is still strongly affected by trip activities which are part of the logistics and planning. The experience is also greatly affected by behavior. All of those components and ultimate the trip experience affect the post-trip project or lack of one. Finally, hopefully, the trip experience and post-trip successes or failures are used to redesign the program iteratively, each year.

The main import of the relational map is to show the crucial nature of redesigning the entire program, not just the curriculum, if a successful trip for $100 \%$ of students and $100 \%$ successful post-trip sustainable initiatives. The effect of the curriculum is limited and success cannot be ensured without redesigning the program components such as logistics, planning, program promotion, and the selection process.

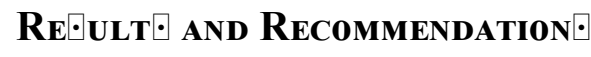

Based on the research synthesis, the design team developed a set of recommendations or design principles to guide any future redesign and prototyping (Table V). The principles can also be used as a heuristic for curricular efficacy. Half the list is unrelated to curricular changes. 
International Journal for Service Learning in Engineering,

Humanitarian Engineering and Social Entrepreneurship

Vol. 13, No. 2, pp. 79-92, Fall 2018

ISSN 1555-9033

TABLE V

Design Principles

\begin{tabular}{|c|c|}
\hline Number & Principles \\
\hline 1 & Create one selection process. \\
\hline 2 & Select students motivated to serve. \\
\hline 3 & Select students whose goals align with the goals of LearnServe. \\
\hline 4 & Select students with minimum acceptable behavior. \\
\hline 5 & Run cohorts or coordinate trip groups by school or region of town. \\
\hline 6 & Design trip activities around a theme. \\
\hline 7 & $\begin{array}{l}\text { Allow students to apply for the trip and theme they prefer instead of being } \\
\text { assigned. }\end{array}$ \\
\hline 8 & Choose sustainable trip activities and projects. \\
\hline 9 & Align trip activities, curricular preparation, and post-trip projects. \\
\hline 10 & Define success for the program, collect data, and measure for each trip and student. \\
\hline 11 & Iterate program design and curriculum annually. \\
\hline 12 & $\begin{array}{l}\text { Elongate curriculum and trip preparation as much as possible throughout school } \\
\text { year. }\end{array}$ \\
\hline 13 & Employ sweat equity so that all students "pay" for the trip. \\
\hline 14 & Spend proportional time on sustainable project education and trip education. \\
\hline 15 & Incorporate post-trip sustainable project work in pre-trip curriculum. \\
\hline 16 & Employ backwards design for curriculum. \\
\hline 17 & Create lean, skills-based curriculum. \\
\hline 18 & Make education active. \\
\hline 19 & Make education experiential. \\
\hline
\end{tabular}




\begin{tabular}{|c|l|}
\hline 20 & Use project-based education. \\
\hline 21 & Use problem-based education. \\
\hline 22 & Use design-based education. \\
\hline 23 & Make education match trip experience and project experience as much as possible. \\
\hline 24 & Personalize the education. \\
\hline 25 & Incorporate language learning. \\
\hline 26 & Incorporate skills education for project work during the trip. \\
\hline 27 & Integrate relation-building with country counterparts during pre-trip sessions. \\
\hline 28 & Employ effective and robust fundraising education. \\
\hline
\end{tabular}

- Selection - There should be one selection process to avoid the use of different selection criteria and to ensure the best students are chosen. In selecting students, LearnServe should select students who are motivated to serve, align with LearnServe goals preventing education and commitment problems before the trip and behavior problems during the trip. Only students with a certain minimum acceptable behavior should be selected. The amount of skills to learn is to great to add behavior education to the list.

- Cohorts - It is better to design trips with students from the same school or region. This allows for bonds formed before the start of the program, eases team dynamics, and focuses intercultural learning on the intercultural exchange trip instead of within the group. Choosing cohorts in the same region also will increase the likelihood that students can attend since meeting locations can be in the same region, and even the same school if it is group from within an entire school.

- Trip Design - Design each trip around a theme or development focus area such as water and sanitation or agriculture. This focuses the learning and can attract different students to different trips. Allow students to apply to the trip that interests them most rather than being forced to a specific trip by their school. Include only sustainable activities on the trip to reinforce their post-trip projects and learning. Align curricular preparation with skills needed for trip activities as well as post-trip sustainable projects.

- Metrics and Evaluation - The design team had to define success in order to conduct the research but LearnServe should do this apart from the design team. Then LearnServe should collect data and measure success for each student and trip and post-trip project. Finally it should iterate and improve the program annually based on these measurements.

- Time and Motivation - All students should invest in the program whether financially or through "sweat equity" in which students do trip-related work to account for scholarships funds received. This is to eliminate the lack of motivation from receiving free money. The 
program should be elongated to occur throughout the year, preferably with applications the spring or summer before the school year starts to allow for a full school year of preparation. This will give more time for needed preparation for the trip and projects as well as improved team bonding and group dynamics from longer interaction and collaboration. Students should spend much more time on the sustainable project than the current model, and education and training for their projects should occur before the trips. Ideally, students should choose sustainable projects before the trips and begin working on them. This allows them more time and more collaboration on sustainable projects with host country counterparts. Right now, the education, the trip, and the projects are too disjoint and much work should be done to align and connect them so that they support and reinforce each other.

- Curriculum - Once success has defined for the LearnServe Abroad program, learning and performance goals can be defined and a curriculum designed backwards. This is the best way to ensure that the educational, preparatory session match the goal of the program. Right now, they are misaligned. The curriculum should be skills-based, active, and experiential. Specifically it should employ project-based learning (PBL) since they will be creating sustainable projects and working on projects. It should employ a subset of PBL called problem-based learning in order to contextualize the learning to the problems they will be solving in through their projects and the solutions to which they will contribute through trip projects and activities. Most importantly it should employ design-based learning (DBL) because designing solutions to social problems is a large part of social entrepreneurship and what they will be doing through their projects and experiencing during the trip. Because each student has different needs and different prior experience, the curriculum should be personalized and the skill-based education should include language learning skills, robust fundraising skills, and skills needed for trip activities and sustainable projects. Students should develop relationships with host country counterparts throughout the year so they have established relationships upon arrival. This will help ease culture shock, improve country knowledge, and minimize isolution. It also means those counterparts should be involved in the trip as much as possible. It also increases the importance of language learning.

\section{Limitation?}

The main limitation is the bias in the research sample. We did not have a qualitatively representative research sample with multiple interviews for each country-role combination (e.g. Paraguay chaperones). Unfortunately, LearnServe controlled recruitment and the research team only had access to contact information given by LearnServe. Their contact information was not representative of all trips and roles.

Second, the people interviewed were biased towards liking LearnServe. Unfortunately, people who did enjoy the experience overall were less likely to be willing to be interviewed and did not return emails or phone calls, and LearnServe did not keep in touch with them.

Third, the research was mostly based on interviews and observations of post-trip sessions. There were no field observations or observations of pre-trip sessions done. Again, this was due to the timeline of LearnServe who refused to wait until the following year in order to allow the researchers to observe pre-trip sessions and a trip. In fact, it was only by chance that the first author observed a post-trip session before this work was commissioned. 
Still, with those three limitations, a plethora of problems was unearthed. It is not clear if having a representative research sample or observing a trip first-hand would have unearthed more problems or greater detail of the problems. Given the limitations, the findings are still excellent and unearth more than the previous program review.

\section{Conclusion}

In this work, we present the use of a human-centered design methodology to guide the designbased implementation research process to redesign the curriculum of a service-learning, social entrepreneurship program for high school students in Washington, DC. Our aim is not just to redesign the curriculum, but to prototype and implement the new curriculum going forward.

Though well-liked by participants, the program has been consistently failing to achieve successful student trips and sustainable student projects for a majority of the students. Redesigning the curriculum is an attempt to address these failings and increase the success rate for the trips and projects.

The most important high-level themes that emerge from our work are attendance, behavior, and rules; personal development; background, promotion, and selection; entrepreneurship and sustainability; motivation and commitment; trip activities; logistics; fundraising; knowledge and culture context; energy and group dynamics; curriculum; skills; and post-trip projects and presentations. Though the goal is to redesign the curriculum, the research uncovered issues related to all of those themes.

Three frameworks were created to help visualize the issues and systems of relationships of program components. Student journey maps through the program highlight a widely variable program and trip experience depending on attendance at preparatory sessions. Design personas were created to guide the prototyping process. Finally a relational map illuminated the most crucial research finding: in order to resolve the problems with the trip experience and post-trip projects, non-curricular parts of the program must be redesigned. In other words, the effect of a curricular redesign, alone, is limited, and it will not resolve all the program issues.

Finally a list of recommendations is made and presented as design principles to guide the prototyping phase. Most notably, LearnServe should define success for the student, the trip, and the post-trip projects and use that to design the curriculum employing backwards-design. Second, the curriculum needs to be active, skills-based, and experiential including project-based learning, problem-based learning, and design-based learning. Third, the skills required for the trip and project require much more time than the current curriculum alots; therefore, the program should be elongated to occur throughout the entire school year. Similarly the post-trip projects need much more time and educational sessions to be successful. Finally, program components and processes such as promotion, selection, logistics, and planning should be redesigned to improve behavior, attendance, motivation, and group dynamics. Most importantly, trip activities, post-trip projects, and education should all be aligned.

Part II of this paper will describe the prototyping process, explore the proposed prototype, and examine early testing results. 
International Journal for Service Learning in Engineering, Humanitarian Engineering and Social Entrepreneurship Vol. 13, No. 2, pp. 79-92, Fall 2018

ISSN 1555-9033

\section{ACKnowledgements}

The author would like to thank the design team of Jocelyn, Chamira, Marnie, and Elisa; the LearnServe research sponsors Scott and Sabine; as well as all of the students, teachers, parents, and chaperones who participated in the interviews, observations, and prototype feedback sessions.

\section{REFERENCES}

1 "Home." Case Foundation. Accessed March 20, 2018. https://casefoundation.org/.

2 "Home." No Kid Hungry. Accessed March 20, 2018. https://www.nokidhungry.org/.

3 "Home - Washington International School." Home - Washington International School. Accessed March 20, 2018. https://www.wis.edu/.

$4 \quad$ "Our Story." Learn-serve.org. Accessed March 20, 2018. http://learn-serve.org/about/our-story.

5 "Strategic Consulting \& Communications for a Digital World." 2018. ICF. ICF International. Accessed March 20. https://www.icf.com/.

$6 \quad$ ICF. 2014. "The Evaluation of LearnServe International." The Evaluation of LearnServe

International. ICF International. http://learn-serve.org/site/assets/2015/06/LearnServe-Evaluation-ReportExecutive-Summary-Final.pdf.

$7 \quad$ "LearnServe Incubator Program." 2018. Learn-Serve.org. LearnServe. Accessed March 20. http://learn-serve.org/learnserve-incubator.

8 “Seeding Social Innovation Program.” 2018. Learn-Serve.org. LearnServe. Accessed March 20. http://learn-serve.org/programs/seeding-social-innovation.

9 "LearnServe Abroad Curriculum.” 2015. Washington, DC: LearnServe.

10 Udoewa, Victor. "YES International Summer Service Program Design for High School Students using Lean Startup." International Journal for Service Learning in Engineering 12, no. 2 (2017).

11 Hall, Erika, and Jeffrey Zeldman. Just enough research. A Book Apart, 2013.

12 Anderman, Eric. "Research Methods: An Overview." Research Methods: An Overview.

December 23, 2009. Accessed April 11, 2016. http://www.education.com/reference/article/researchmethods-an-overview/.

13 "Explanation - What Is Design-Based Research (DBR)?" Explanation - What Is Design-Based Research (DBR)? 2006. Accessed April 11, 2016. http://dbr.coe.uga.edu/explain01.htm.

$14 \quad$ "Design-Based Research: An Emerging Paradigm for Educational Inquiry." Educational Researcher 32, no. 1 (2003): 5-8. Accessed April 11, 2016. doi:10.3102/0013189x032001005.

$15 \quad$ Tatar, Deborah. "The design tensions framework." Human-Computer Interaction 22, no. 4 (2007): 413-451.

16 Penuel, William R. "Infrastructuring As a Practice for Promoting Transformation and Equity in Design-Based Implementation Research." (2015).

17 Penuel, William R., and Angela Haydel DeBarger. "A Research-Practice Partnership to Improve Formative Assessment in Science."

18 Roschelle, Jeremy, Jennifer Knudsen, and Stephen Hegedus. "From new technological infrastructures to curricular activity systems: Advanced designs for teaching and learning." In Designs for learning environments of the future, pp. 233-262. Springer US, 2010.

19 Coburn, Cynthia E., Jennifer L. Russell, Julia Heath Kaufman, and Mary Kay Stein. "Supporting sustainability: Teachers' advice networks and ambitious instructional reform." American Journal of Education 119, no. 1 (2012): 137-182.

20 Sabelli, Nora, and Chris Dede. "Empowering Design-Based Implementation Research: The Need for Infrastructure."

$21 \quad$ "Design Based Implementation Research." DBIR -...Principles. 2016. Accessed April 11, 2016. http://learndbir.org/principles. 
International Journal for Service Learning in Engineering, Humanitarian Engineering and Social Entrepreneurship Vol. 13, No. 2, pp. 79-92, Fall 2018

ISSN 1555-9033

22 Jacobson, Robert, ed. "Chapter 4: Human-centered Design." In Information Design, by Mike Cooley, 59-81. Cambridge: MIT Press, 2000.

23 IDEO.org. HCD Toolkit. San Francisco: IDEO.org, 2013. 2nd edition.

$24 \quad$ IDEO.org. The Field Guide to Human-centered Design. San Francisco: IDEO.org, 2015. 1st edition.

25 Friedman, Batya, and David Hendry. "The envisioning cards: a toolkit for catalyzing humanistic and technical imaginations." In Proceedings of the SIGCHI conference on human factors in computing systems, pp. 1145-1148. ACM, 2012.

$26 \quad$ Simonsen, Jesper, and Finn Kensing. "Using ethnography in contextual design." Communications of the ACM 40, no. 7 (1997): 82-88.

$27 \quad$ Millen, David R. "Rapid ethnography: time deepening strategies for HCI field research." In Proceedings of the $3 \mathrm{rd}$ conference on Designing interactive systems: processes, practices, methods, and techniques, pp. 280-286. ACM, 2000.

$28 \quad$ Barab, Sasha A., Michael K. Thomas, Tyler Dodge, Kurt Squire, and Markeda Newell. "Critical design ethnography: Designing for change." Anthropology \& Education Quarterly 35, no. 2 (2004): 254268.

29 Bang, Megan, Douglas Medin, Karen Washinawatok, and Shannon Chapman. "Innovations in culturally based science education through partnerships and community." In New Science of Learning, pp. 569-592. Springer New York, 2010.

$30 \quad$ Penuel, William R., Samuel Severance, Raymond Johnson, Heather Leary, and Susan Miller. "The Emergence of New Objects in Co-Design: A Cultural-Historical Activity Theoretical Analysis." Proceedings of the 11th International Conference of the Learning Sciences, June 2014. Accessed April 12, 2016. http://learndbir.org/resources/Negotiating the Object in CoDesign.pdf.

$31 \quad$ Muller, Michael J., Daniel M. Wildman, and Ellen A. White. "Taxonomy of Participatory Design Practices." Posters and Short Talks of the 1992 SIGCHI Conference on Human Factors in Computing Systems - CHI '92, 1992. Accessed April 12, 2016. doi:10.1145/1125021.1125053.

$32 \quad$ Muller, Grudin, Jonathan, and John Pruitt. "Personas, participatory design and product development: An infrastructure for engagement." In PDC, pp. 144-152. 2002.

33 "Influential Theories of Learning | Education | United Nations Educational, Scientific and Cultural Organization." Influential Theories of Learning | Education | United Nations Educational, Scientific and Cultural Organization. 2016. Accessed April 22, 2016.

http://www.unesco.org/new/en/education/themes/strengthening-education-systems/qualityframework/technical-notes/influential-theories-of-learning/.

$34 \quad$ Hung, Woei, David H. Jonassen, and Rude Liu. "Problem-based learning." Handbook of research on educational communications and technology 3 (2008): 485-506.

$35 \quad$ Allen, Deborah E., Richard S. Donham, and Stephen A. Bernhardt. "Problem-based learning." New Directions for Teaching and Learning 2011, no. 128 (2011): 21-29.

$36 \quad$ "Seize the Summer." High School Summer Abroad | CIEE. Accessed March 25, 2018. https://www.ciee.org/go-abroad/high-school-study-abroad/summer.

37 "High School Summer Abroad Programs." 2018. Go Overseas. Go Overseas. Accessed March 25. https://www.gooverseas.com/high-school-abroad/summer.

$38 \quad$ Projects Abroad Inc. 2018. "Volunteer Abroad Programs for Teenagers | Projects Abroad." Volunteer Overseas. Projects Abroad. Accessed March 25. https://www.projects-abroad.org/how-itworks/high-school-volunteers/.

$39 \quad$ Kwan, Anna. "Problem-based learning." The Routledge international handbook of higher education (2009): 91-107.

$40 \quad$ Loyens, Sofie, Paul A. Kirschner, and Fred Paas. "Problem-based learning." 2010.

41 Merriam, Sharan B. "Andragogy and self-directed learning: Pillars of adult learning theory." New directions for adult and continuing education 2001, no. 89 (2001): 3-14. 
International Journal for Service Learning in Engineering, Humanitarian Engineering and Social Entrepreneurship Vol. 13, No. 2, pp. 79-92, Fall 2018

ISSN 1555-9033

42 Smith, Mark K. Malcolm Knowles, informal adult education, self-direction and andragogy. Infed, the Encyclopedia of informal education, 2002.

$43 \quad$ Stein, David. "Situated Learning in Adult Education. ERIC Digest No. 195." (1998).

44 Lave, Jean, and Etienne Wenger. Situated learning: Legitimate peripheral participation. Cambridge university press, 1991.

$45 \quad$ Gee, James Paul. "What video games have to teach us about learning and literacy." Computers in Entertainment (CIE) 1, no. 1 (2003): 20-20.

$46 \quad$ Stavredes, Tina. "Just-in-time learning." In Encyclopedia of distance learning, pp. 1162-1166. IGI Global, 2005.

$47 \quad$ Wiggins, Grant, and Jay McTighe. "What is backward design." Understanding by design 1 (1998): 7-19.

$48 \quad$ Daugherty, Kimberly K. "Backward course design: making the end the beginning." American journal of pharmaceutical education 70, no. 6 (2006): 135.

49 Childre, Amy, Jennifer R. Sands, and Saundra Tanner Pope. "Backward design: Targeting depth of understanding for all learners." Teaching Exceptional Children 41, no. 5 (2009): 6-14.

$50 \quad$ Mapstone, J., D. Elbourne, and I. Roberts. "Strategies to improve recruitment to research studies." Cochrane Database Syst Rev 2 (2007).

$51 \quad$ Patel, Maxine X., Victor Doku, and Lakshika Tennakoon. "Challenges in Recruitment of Research Participants.” Advances in Psychiatric Treatment 9, no. 3 (2003): 229-38. doi:10.1192/apt.9.3.229.

52 Zimmerman, Barry J., and Maria K. Dibenedetto. "Mastery learning and assessment: Implications for students and teachers in an era of high-stakes testing." Psychology in the Schools 45, no. 3 (2008): 206-216.

$53 \quad$ Clariana, Roy. "Pace in Mastery-Based Computer-Assisted Learning." British Journal of Educational Technology 28, no. 2 (1997): 135-137.

$54 \quad$ Maton, Karl. "Cumulative and segmented learning: Exploring the role of curriculum structures in knowledge-building." British Journal of Sociology of Education 30, no. 1 (2009): 43-57.

$55 \quad$ Hailikari, Telle, Nina Katajavuori, and Sari Lindblom-Ylanne. "The relevance of prior knowledge in learning and instructional design." American Journal of Pharmaceutical Education 72, no. 5 (2008): 113.

56 Walker, D. J., and E. Palmer. "The relationship between student understanding, satisfaction and performance in an Australian engineering programme." Assessment \& Evaluation in Higher Education 36, no. 2 (2011): 157-170.

57 Sockalingam, Nachamma. "The Relation between Student Satisfaction and Student Performance in Blended Learning Curricula." International Journal of Learning 18, no. 12 (2012).

58 Picciano, Anthony G. "Beyond student perceptions: Issues of interaction, presence, and performance in an online course." Journal of Asynchronous learning networks 6, no. 1 (2002): 21-40.

59 Carini, Robert M., George D. Kuh, and Stephen P. Klein. "Student engagement and student learning: Testing the linkages." Research in higher education 47, no. 1 (2006): 1-32.

60 Liddicoat, Anthony, and Chantal Crozet. "Teaching culture as an itegrated-ie. integrated-part of language teaching: an introduction." Australian Review of Applied Linguistics. Series S 14 (1997): 1.

61 Risager, Karen. Language and culture pedagogy: From a national to a transnational paradigm. Vol. 14. Multilingual Matters, 2007.

62 Risager, Karen. Language and culture: Global flows and local complexity. Multilingual matters, 2006.

$63 \quad$ Sscott. "Knowledge Based Curriculum vs Skills Based Curriculum." Target Maps. June 03, 2015. Accessed April 19, 2018. http://targetmaps.co.uk/knowledge-based-curriculum-vs-skills-basedcurriculum/.

$64 \quad$ Fleetham, Mike. "Skills Based Learning." Thinking Classroom. 2018. Accessed April 19, 2018. https://www.thinkingclassroom.co.uk/ThinkingClassroom/SkillsBasedLearning.aspx. 
International Journal for Service Learning in Engineering, Humanitarian Engineering and Social Entrepreneurship Vol. 13, No. 2, pp. 79-92, Fall 2018

ISSN 1555-9033

$65 \quad$ "Knowledge and Skills-Based Learning." Fortress Learning. 2018. Accessed April 19, 2018. https://fortresslearning.com.au/cert-iv-content/deliver/knowledge-and-skills-based-learning/.

$66 \quad$ "Sustainable Development Goals: 17 Goals to Transform Our World." United Nations. 2015. Accessed April 19, 2018. https://www.un.org/sustainabledevelopment/sustainable-development-goals/. 67 Ronkko, Kari. "An empirical study demonstrating how different design constraints, project organization and contexts limited the utility of personas." In System Sciences, 2005. HICSS'05. Proceedings of the 38th Annual Hawaii International Conference on, pp. 220a-220a. IEEE, 2005. https://pdfs.semanticscholar.org/f622/d91fbbde9c175adc5e0a3358756894737cdf.pdf\#page=211. $68 \quad$ Chapman, Christopher N., Edwin Love, Russell P. Milham, Paul ElRif, and James L. Alford. "Quantitative evaluation of personas as information." In Proceedings of the Human Factors and Ergonomics Society Annual Meeting, vol. 52, no. 16, pp. 1107-1111. Sage CA: Los Angeles, CA: SAGE Publications, 2008. http://www.academia.edu/download/42923141/reprint-hfes08-chapman-love-milhamelrif-alford.pdf.

$69 \quad$ Long, Frank. "Real or imaginary: The effectiveness of using personas in product design." In Proceedings of the Irish Ergonomics Society Annual Conference, vol. 14. Irish Ergonomics Society, 2009.

https://s3.amazonaws.com/media.loft.io/attachments/Long\%20(2009)\%20Real\%20or\%20Imaginary.pdf. 